\title{
Shear measurements across the northern margin of Whillans Ice Stream
}

\author{
C.J. VAN DER VEEN, K.C. JEZEK, L. STEARNS ${ }^{\dagger}$ \\ Byrd Polar Research Center and Department of Geological Sciences, The Ohio State University, 1090 Carmack Road, \\ Columbus, Ohio 43210-1002, USA \\ E-mail: cjvdv@ku.edu
}

\begin{abstract}
Field measurements of surface deformation across the northern shear margin of Whillans Ice Stream, West Antarctica, were analyzed to better understand the processes controlling the position and migration of this margin. Four lines of poles extending $\sim 6 \mathrm{~km}$ from the interstream ridge into the shear margin were installed in November 1997 and resurveyed in January 2000, using GPS methods. A band of arcuate crevasses form where the surficial shear stress reaches $\sim 130 \mathrm{kPa}$, and a chaotic zone of crevassing occurs where this stress reaches a maximum of $\sim 270 \mathrm{kPa}$. Inspection of the RAMP mosaic indicates that the band of arcuate crevasses is separated from the chaotic zone by a narrow zone $(\sim 250 \mathrm{~m})$ with a relatively undisturbed surface morphology. A force-budget analysis suggests the transition from no basal sliding to full basal sliding must be restricted to a relatively narrow band, $\sim 1.5 \mathrm{~km}$ wide beneath the chaotic zone. On the ice stream, resistance from the bed is near zero and the driving stress is balanced by gradients in lateral shearing. Basal drag reaches a maximum close to the shear margin where basal conditions transition from well lubricated (beneath the ice stream) to no basal slip (beneath the ridge). The zone of elevated basal drag is $\sim 4 \mathrm{~km}$ wide. Within this zone, lateral drag is reduced and becomes increasingly restricted to upper layers. Localized meltwater production under the region of elevated basal drag is similar in magnitude to melting under the ice stream. The uniform bed morphology, inferred from radar sounding, excludes the presence of abundant basal water either in a water film at the glacier bed or in a thick saturated till layer. This suggests that most of the meltwater produced under the shear margin is diverted towards the ice stream, possibly playing a crucial role in maintaining lubricated conditions allowing streaming flow.
\end{abstract}

\section{INTRODUCTION}

Recent studies show that contemporary ice sheets, as well as ice sheets throughout the Quaternary, are susceptible to changes on decadal to millennial timescales (Joughin and others, 2002; Hemming, 2004; Stearns and others, 2005). Changes in the geometry of ice sheets have a direct effect on global sea level as more mass is transferred from the frozen reservoirs to the world's oceans. Sea level is currently rising and grounded ice is likely to be a major contributor to sealevel rise in the future (Church and others, 2001; Huybrechts and others, 2004). Most of the ice discharge from grounded ice sheets is by means of ice streams and outlet glaciers. In West Antarctica, drainage is achieved primarily through meandering fast-moving ice streams embedded in the main body of more sluggishly moving ice. These ice streams, in particular those on the Siple Coast draining into the Ross Ice Shelf, have been the subject of extensive studies and field campaigns since the early 1980s (e.g. Alley and Bindschadler, 2001). From these studies, it has become evident that ice streams are one of the most critical components of the West Antarctic ice sheet system, yet they are also the least understood.

The causes for ice streaming, and the mechanical constraints on its dimensions and high speeds, must be understood if observed imbalances and future behavior of the West Antarctic ice sheet are to be comprehended. Ice

*Present address: Department of Geography, University of Kansas, 213 Lindley Hall, 1475 Jayhawk Blvd, Lawrence, Kansas 66045-7613, USA.

†Present address: Climate Change Institute, University of Maine, 303 Bryand Global Sciences Center, Orono, Maine 04469-5790, USA. streams are characterized by high speeds achieved under exceptionally low gravitational driving stress. On Whillans Ice Stream (formerly known as Ice Stream B), the driving stress ranges between 10 and $20 \mathrm{kPa}$, while speeds up to $800 \mathrm{~m} \mathrm{a}^{-1}$ have been measured (Whillans and others, 2001). This observation indicates that resistance to flow must be exceptionally small, most likely due to a weakening of subglacial sediments (Alley and others, 1986; Tulaczyk and others, 2001). Whillans and others (2001) presented an estimate of the budget of forces along the length of Whillans Ice Stream and concluded that most or all of the driving stress is balanced by drag originating at the lateral margins where faster-moving ice shears past the almost stagnant interstream ridges. Subsequent studies (Joughin and others, 2002; Stearns and others, 2005) have confirmed this result.

Perhaps the most striking characteristic of the active Siple Coast ice streams is the 100-fold contrast in speed between the fast-moving ice streams and adjacent near-stagnant interstream ridges. The lateral shear margins represent the narrow along-flow zone over which the speed contrast is developed. Strong shearing across vertical planes paralleling the flow results in bands of severely crevassed ice that can be traced from deep in the interior (Hodge and Doppelhammer, 1996; Jezek, 1999) to beyond the grounding line on the Ross Ice Shelf (Fahnestock and Bamber, 2001). One unresolved question is what determines the location of shear margins, and how these margins migrate laterally. In earlier models of ice-stream flow, it was assumed that the motion of ice streams was controlled from the bed, by the extent of contact with the underlying rock, or by the strength of possible mobile sediments under the ice. However, several 
Table 1. Whillans Ice Stream survey positions

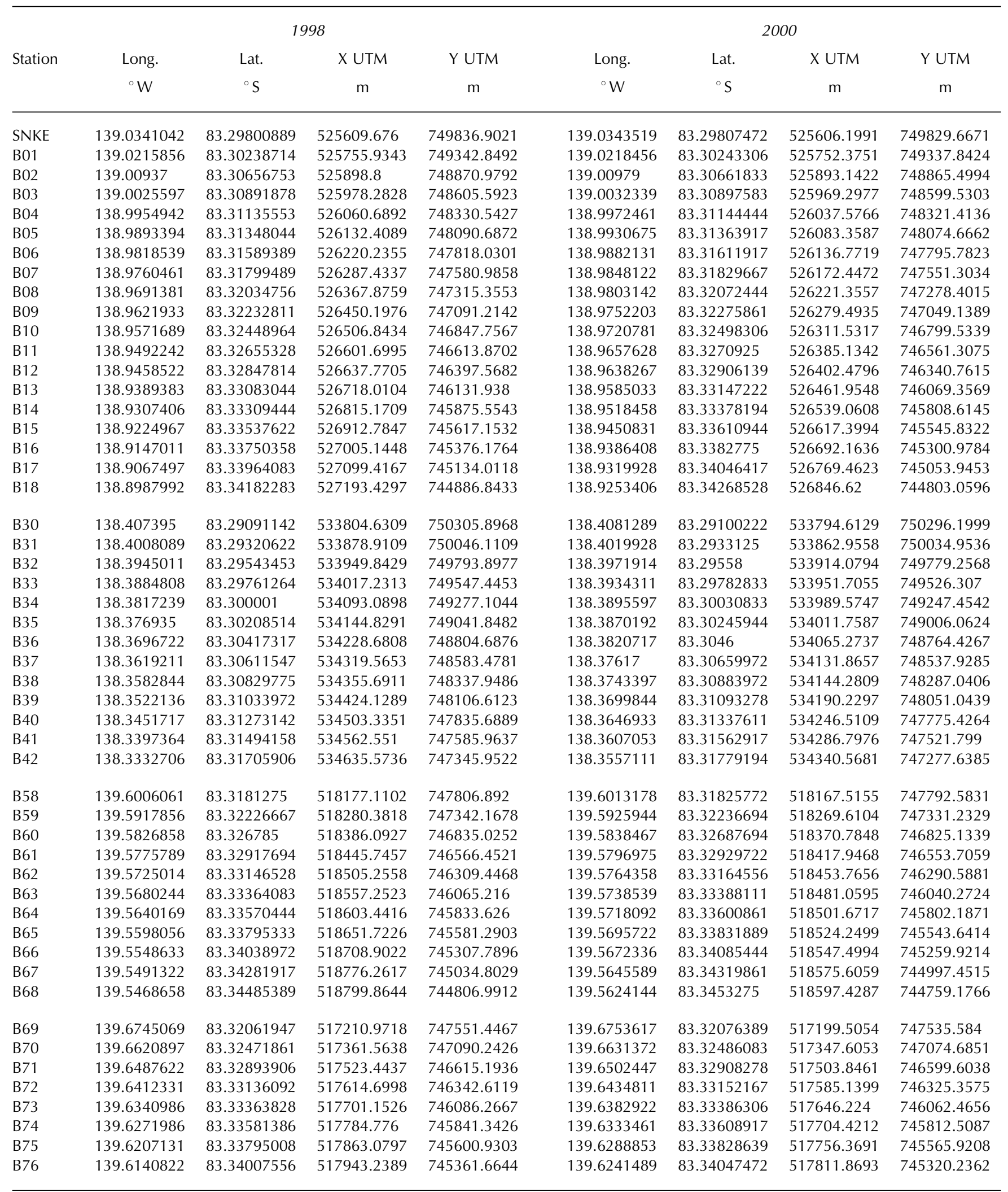

studies have indicated that the active ice streams are largely controlled from their sides (Bindschadler and others, 1987; Echelmeyer and others, 1994; MacAyeal and others, 1995; Whillans and Van der Veen, 1997; Whillans and others, 2001; Joughin and others, 2002). The observation that shear margins are rather narrow indicates that the transition between well-lubricated flow on the ice stream to a flow regime dominated by basal friction on the interstream ridge must be rather sharp. On the ice stream, vertical shear is negligible and the dominant strain rate is generated by lateral shear. On the ridges, lateral shear is insignificant and flow is dominated by vertical shear. The shear margins represent the region where the shear stress is transformed from acting on vertical planes parallel to the sides to shear 
Table 1. (continued)

\begin{tabular}{|c|c|c|c|c|c|c|c|c|}
\hline \multirow{3}{*}{ Station } & \multicolumn{4}{|c|}{1998} & \multicolumn{4}{|c|}{2000} \\
\hline & Long. & Lat. & X UTM & Y UTM & Long. & Lat. & X UTM & Y UTM \\
\hline & ${ }^{\circ} \mathrm{W}$ & ${ }^{\circ} \mathrm{S}$ & $\mathrm{m}$ & $\mathrm{m}$ & ${ }^{\circ} \mathrm{W}$ & ${ }^{\circ} \mathrm{S}$ & $\mathrm{m}$ & $\mathrm{m}$ \\
\hline O38 & 138.9821911 & 83.31586664 & 526215.9623 & 747821.2235 & 138.9885139 & 83.31609417 & 526132.9624 & 747798.7078 \\
\hline $\mathrm{O} 40$ & 138.9813306 & 83.31587581 & 526227.1026 & 747819.8097 & 138.9876578 & 83.31610028 & 526144.0566 & 747797.6381 \\
\hline O49 & 138.9821533 & 83.31574675 & 526216.921 & 747834.5819 & 138.9883356 & 83.31596611 & 526135.7767 & 747812.9138 \\
\hline $\mathrm{O} 53$ & 138.9808875 & 83.31588158 & 526232.834 & 747818.9636 & 138.9872497 & 83.31610778 & 526149.3267 & 747796.6164 \\
\hline O54 & 138.9817753 & 83.31587117 & 526221.3451 & 747820.5294 & 138.98811 & 83.31609611 & 526138.2 & 747798.3079 \\
\hline O55 & 138.9820386 & 83.31571186 & 526218.5472 & 747838.4222 & 138.9881928 & 83.31593028 & 526137.7704 & 747816.8469 \\
\hline O63 & 138.9822681 & 83.31577739 & 526215.3115 & 747831.2158 & 138.9884831 & 83.31599833 & 526133.7357 & 747809.3857 \\
\hline O64 & 138.9825261 & 83.31586339 & 526211.6243 & 747821.7383 & 138.9888542 & 83.31609417 & 526128.5433 & 747798.8619 \\
\hline O65 & 138.9823672 & 83.31580622 & 526213.911 & 747828.044 & 138.9886167 & 83.31602611 & 526131.8925 & 747806.3471 \\
\hline S18 & 139.0661017 & 83.28313542 & 525248.6499 & 751510.4547 & 139.0662581 & 83.28319686 & 525246.379 & 751503.6677 \\
\hline S20 & 139.2121883 & 83.21448961 & 523579.4163 & 759231.5342 & 139.2122958 & 83.21454186 & 523577.8183 & 759225.748 \\
\hline S21 & 139.2513461 & 83.17002889 & 523213.5122 & 764208.4183 & 139.2516289 & 83.1700705 & 523209.6187 & 764203.889 \\
\hline S22 & 139.2900681 & 83.12544461 & 522847.0804 & 769198.757 & 139.2903006 & 83.12547483 & 522843.8748 & 769195.4767 \\
\hline S23 & 139.3281417 & 83.08103117 & 522482.112 & 774169.6199 & 139.3282269 & 83.08105911 & 522480.8752 & 774166.5349 \\
\hline
\end{tabular}

stress acting on planes parallel to the bed (Whillans and Van der Veen, 1997, 2001). The nature of this transfer is not clear, however, due to the complexity of this stress transfer.

In the studies referred to above, the role of lateral drag is estimated from observations made on the ice stream itself. A different approach was adopted by Whillans and Van der Veen (2001) who considered the stagnant ridges adjacent to the ice stream where measured speeds are typically of the order of a few meters per year (Whillans and Van der Veen, 1993). They supposed that if lateral drag supports all or part of the driving stress on the ice stream, then there must be a region of large basal drag elsewhere. It then follows that lateral drag supporting the ice stream must be transferred to basal drag under the interstream ridges, such that, integrated over the full width of the ice stream and adjacent ridges, the integrated basal drag equals the total driving force. Another possibility would be that the reduced basal drag under one part of the ice stream is accompanied by increased basal drag elsewhere under the ice stream. However, this requires along-flow transfer of flow resistance through gradients in longitudinal stress. Whillans and Van der Veen (1993) and Whillans and others (2001) used measurements of surface velocity along the length of Whillans Ice Stream to show that longitudinal stress gradients are unimportant to the largescale dynamics of this ice stream, indicating no along-flow transfer of resistance over larger distances. On a local scale, such as along the strain grid near the UpB Camp (located near the center of the ice stream between the 'snake' and 'Dragon'), gradients in longitudinal stress can become important (Hulbe and Whillans, 1997; see also Price and others, 2002).

The objective of the present contribution is to further investigate the transfer of lateral drag to basal drag under the interstream ridge using previously unpublished measurements of surface speed derived from strain grids in the shear margins of three West Antarctic ice streams. Here, we focus on results for Whillans Ice Stream; results for the strain grids on Bindschadler and MacAyeal Ice Streams will be presented in a future paper.

\section{MEASUREMENTS}

Four lines of poles were installed at the northern margin of Whillans Ice Stream, extending $\sim 6 \mathrm{~km}$ from the interstream ridge into the shear margin (the 'snake'). Poles were placed $\sim 250 \mathrm{~m}$ apart, approximately perpendicular to the direction of ice-stream flow. Due to intense crevassing at shear margins, all surveys were conducted on foot by a four- or five-person rope team. The global positioning system (GPS) equipment and a Trimble 4000SSI receiver were pulled on a sled with the compact L1/L2 antenna mounted on a pole. The transects were initially surveyed in November 1998 and again in January 2000. GPS surveying was carried out using the 'stop-and-go' kinematic method, following Hulbe and Whillans (1993, 1994). A continuously recording GPS receiver was located at the base camp (SNKE), and operated for the duration of each survey (typically a week or so). A fixed control in each transect, usually the pole closest to the base station, acted as a tie point between the line of poles and the base station. Kinematic GPS data (between poles) and the static GPS data at each subsequent pole were linked to this fixed point. The base station collected data at $30 \mathrm{~s}$ intervals. All other static (at each pole and the fixed control station) and kinematic surveys collected data at $5 \mathrm{~s}$ intervals.

The base station and fixed control stations were postprocessed using the GIPSY-OASIS II software package, which improves the precision of the point position (Zumberge and others, 1997). The program incorporates the Earth's orientation and precise satellite orbit, as well as clock solutions derived from NASA Jet Propulsion Laboratory's independent analysis of global fiducial stations. Formal $1 \sigma$ (rms) uncertainties for the daily solutions are typically better than $0.01 \mathrm{~m}$ for the $\mathrm{x}, \mathrm{y}$ and $\mathrm{z}$ positions (Spikes and others, 2003). The daily solutions are referenced to the International Terrestrial Reference Frame 1996 (ITRF96) using the World Geodetic System 1984 (WGS84) ellipsoidal model. The stop-and-go kinematic survey data for each transect were processed relative to the fixed control station using Trimble's 


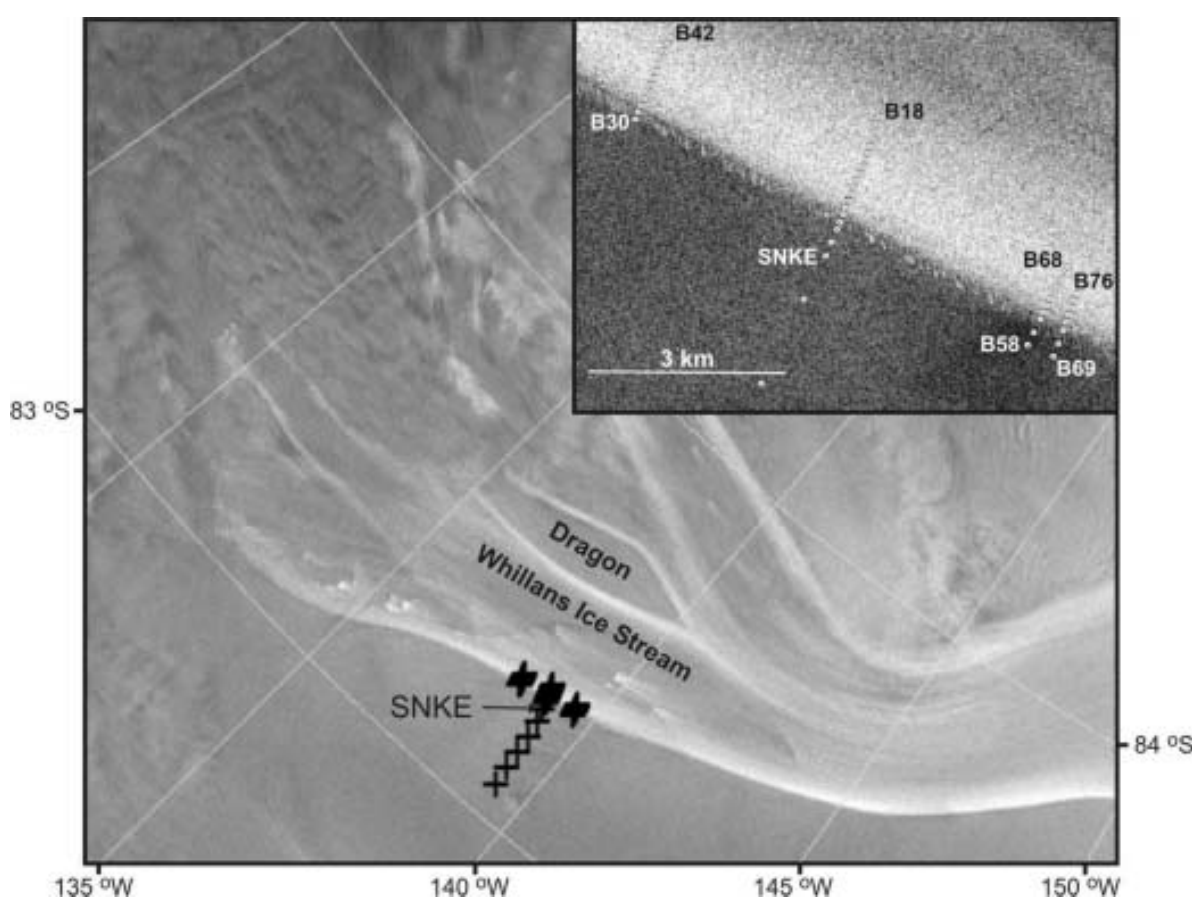

Fig. 1. Location of survey lines across the northern shear margin of Whillans Ice Stream overlain on a portion of the RADARSAT-1 Antarctic Mapping Project (RAMP) mosaic.

proprietary software and precise satellite orbits. This processing procedure has been successfully used to calculate kinematic solutions over baselines of several hundred kilometers during airborne survey work and extended ground traverses in West Antarctica, and should be appropriate for the short baselines used in this study (Spikes and others, 2003).

Primary products from the GPS surveys are positions in geodetic coordinates. For further analysis, these coordinates were transformed to Universal Transverse Mercator (UTM) coordinates using the coordinate transformation routine available in ENVI. These coordinates were subsequently transformed to a local Cartesian system with the origin defined by the position of the base station during the first survey, and the $x$ axis approximately in the direction of icestream discharge. For both surveys, these positions are given in Table 1.

\section{RESULTS}

\section{Elevation and surface speed}

Three of the four pole lines are considered in this study (Fig. 1). The short transect formed by poles B69-B76 is not discussed here because it is very close to transect B58-B68 and results for both lines are essentially the same. Relative elevations and derived velocities are shown in Figure 2. The origin of the local coordinate system is at the base station (SNKE) and the $x$ axis is chosen to be the direction of speed nearest to the center of the ice stream (i.e. at station B18). Crevasse patterns indicated in this and following figures are discussed in a later section.

In contrast to the southern shear margin where elevation contours are mostly parallel to the direction of ice-stream flow (Whillans and Van der Veen, 2001, fig. 4), the contour map in Figure 2 suggests a significant local component of

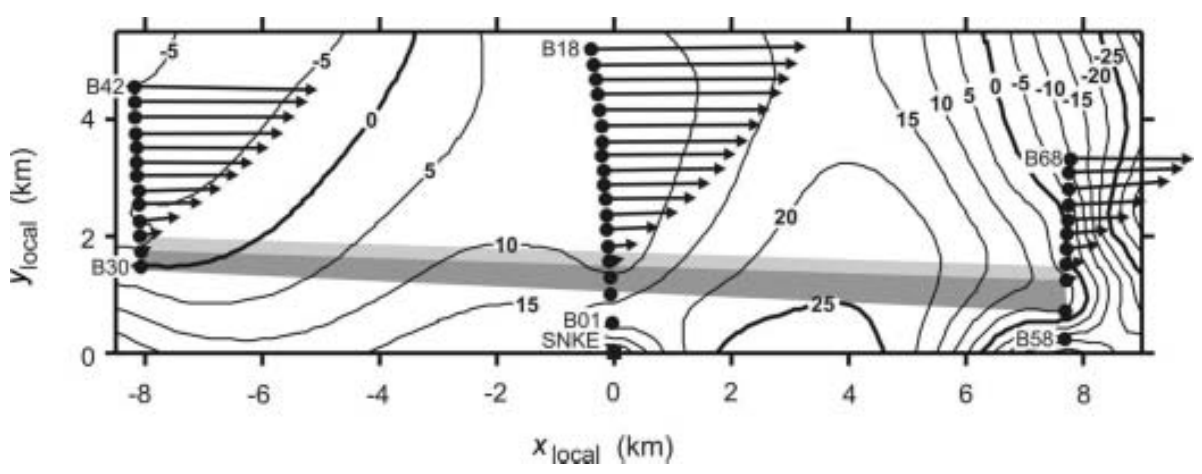

Fig. 2. Surface elevation contours obtained from gridding GPS measurements at survey stations (black dots; estimated elevation accuracy $0.01 \mathrm{~m}$ ). Arrows represent ice velocity at survey stations. The dark gray band corresponds to the zone of arcuate crevasses, while the lighter gray band represents a narrow zone of relatively undisturbed surface topography, separating the arcuate crevasses from the chaotic zone. 

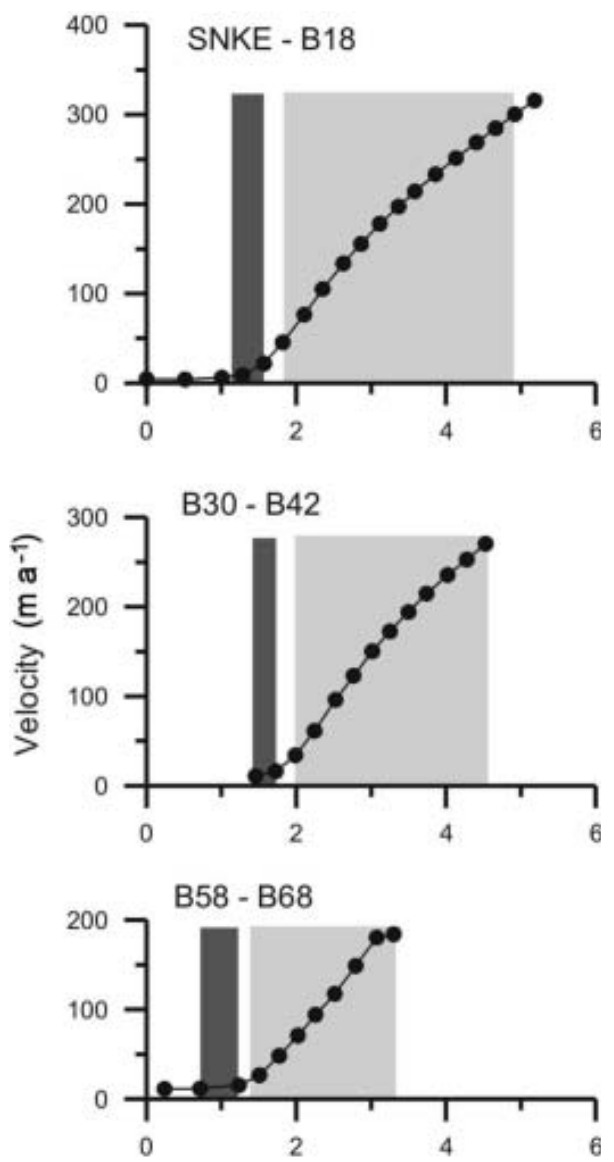

Distance along transect $(\mathrm{km})$

Fig. 3. Measured surface speed along the three transects. The dark gray band corresponds to the zone of arcuate crevasses, while the light gray band represents the chaotic zone.

driving stress acting in the flow direction. At the most inboard station, B18, the local along-flow driving stress is $\sim 22 \mathrm{kPa}$, or about twice the width-averaged driving stress on the ice stream proper. At the eastern edge of the study area (near transect B58-B68), surface slopes are even steeper, resulting in exceptionally large driving stress $(\sim 90 \mathrm{kPa})$. (Note that elevations along the B69-B76 transect are incorporated into the contour map shown in Figure 2, so the steep gradients in elevation near $x=8 \mathrm{~km}$ are not an edge effect of the gridding routine. Of course, due to the lack of stations between the three lines, the exact shape of the contours in these regions is poorly constrained.) The significance of the comparatively large driving stress is not entirely clear, as this survey was conducted mostly in the chaotic zone where the surface topography is highly irregular. Moreover, inspection of elevations from the OSU (Ohio State University) digital elevation model (Jezek and others, 1999; Liu and others, 1999) shows these slopes to be very localized. Considered over greater distances $(\sim 10 \mathrm{~km})$, the ice-stream parallel component of surface slope on the ridge is small, resulting in a lower driving stress of $\sim 12 \mathrm{kPa}$.

Velocities measured along the three transects are shown in Figure 3. The speed rapidly increases from near zero on the interstream ridge to several hundred meters per year at the inboard edge of the chaotic zone. Near the center line of Whillans Ice Stream, ice speed is $450 \mathrm{~m} \mathrm{a}^{-1}$ (Whillans and Van der Veen, 1993), i.e. over a 3-4 km narrow zone, ice

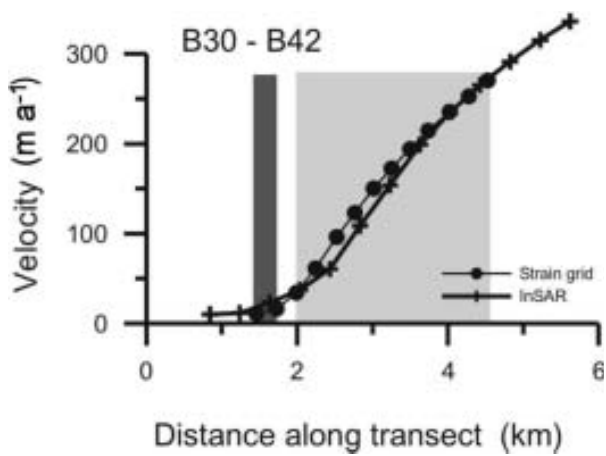

Fig. 4. Comparison between GPS-derived velocities along the B30-B42 transect and velocities obtained from interferometry.

speed increases from essentially zero to about $75 \%$ of the center line speed.

Figure 4 shows a comparison between the velocities along the B30-B42 gridline and those derived from interferometric synthetic aperture radar (InSAR) (Joughin and others, 2002). The latter dataset covers much of the Siple Coast ice streams, revealing a complex network of feeder tributaries (Joughin and others, 1999). The velocity field was derived from 6 days of repeat coverage from the RADARSAT-1 mission in October 1997, which achieved the first complete high-resolution $(25 \mathrm{~m})$ radar imaging of the entire Antarctic continent (Jezek, 1999, 2003). Generally, there is a good agreement between the two unrelated velocity datasets; the different shapes of the profiles likely reflect that the two profiles are not exactly overlapping.

\section{Shear strain rate and shear stress}

The lateral shearing rate and associated shear stress are necessary to determine the importance of lateral drag on the dynamics of the ice stream. At the surface, the dominant velocity gradient is $\partial u / \partial y$, where $u$ represents the alongflow component of velocity, and $y$ the horizontal direction perpendicular to the ice stream. The shear strain rate may then be calculated from

$$
\dot{\varepsilon}_{x y}=\frac{1}{2} \frac{\partial u}{\partial y}
$$

with the corresponding surface shear stress

$$
R_{x y}=B \dot{\varepsilon}_{x y}^{1 / n},
$$

where $B$ is the temperature-dependent rate factor and $n=3$ is the flow-law exponent. For the rate factor, the value $B=700 \mathrm{kPa}^{1 / 3}$ is used, appropriate for the colder upper layers (Whillans and Van der Veen, 2001). Results of these calculations are shown in Figures 5 and 6.

The shear strain rate increases rapidly from zero on the interstream ridge to a maximum of $0.06 \mathrm{a}^{-1}$ at the edge of the chaotic zone. The corresponding near-surface shear stress is $\sim 270 \mathrm{kPa}$.

\section{Comparison with radar sounding}

In 1998, a surface-based ice-penetrating radar system was used to measure surface and bed elevations as well as internal layers across the margins of Whillans and MacAyeal Ice Streams (Raymond and others, 2006). In the margin of Whillans Ice Stream, radar profiles extend from stations B7 and B68 onto the interstream ridge. For both transects, the position of the shear margin does not appear to be associated with any significant bed topography. 

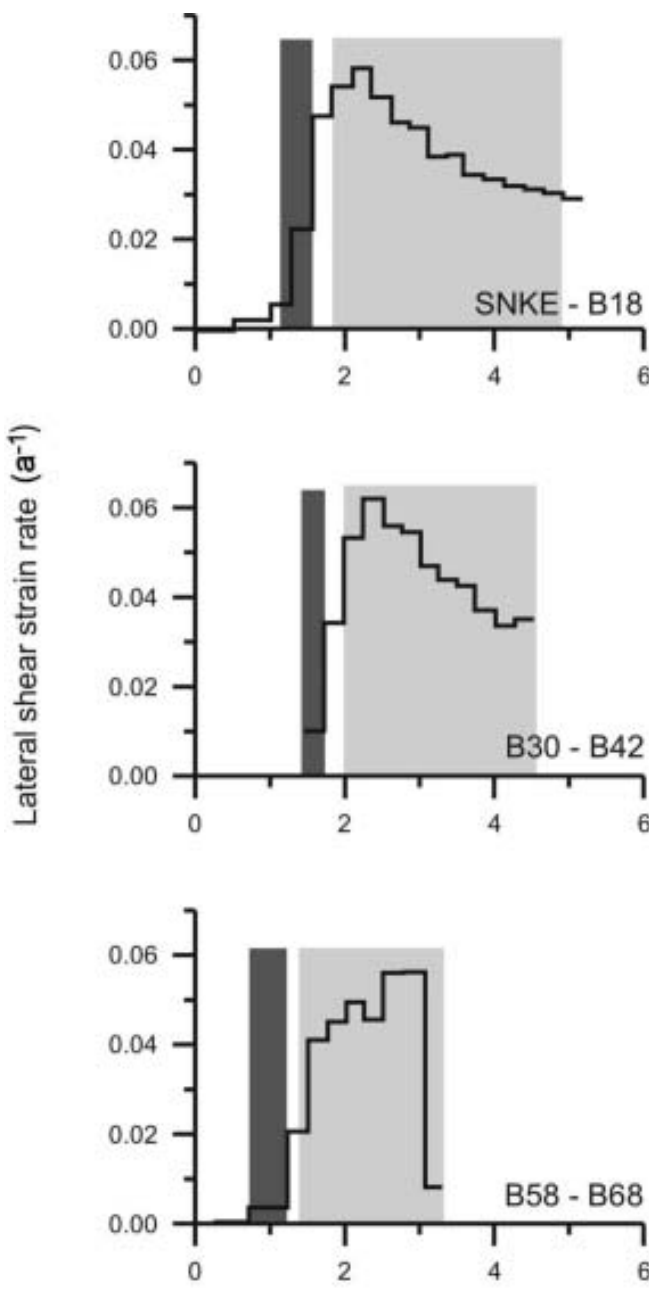

Distance along transect $(\mathrm{km})$

Fig. 5. Derived shear strain rate along the three transects. The dark gray band corresponds to the zone of arcuate crevasses, while the light gray band represents the chaotic zone.

Across the northern shear margin of Whillans Ice Stream, internal layers beneath the heavily crevassed chaotic zone are warped but remain continuous. None of the radar profiles show a change in bed reflectivity or energy returned from internal layers, as would be expected with a transition from a well-lubricated bed under the ice stream to the highbasal-drag ridge (Raymond and others, 2006). The implication is that the region of maximum shear does not directly overlie a transition in bed morphology. A similar result was obtained by Catania and others (2003) who considered bed reflectivity across several relict ice-stream margins. Their measurements show a jump in bed reflectivity from low to high values several kilometers to the ice-stream side of the outermost buried crevasses. They interpret this jump in reflectivity as a transition from frozen to thawed basal conditions. While it is possible that the transition from frozen to thawed conditions has migrated inward since the shutdown of the ice streams studied, as noted by Catania and others (2003), the results of Raymond and others (2006) suggest that the transition from streaming flow to internal deformation on the ridges may be more complex and involve a broader region than suggested by measurements of surface speed only.

\section{Crevasse patterns}

Based on aerial photography, Vornberger and Whillans (1986) provided a description of visible features across the margins of Whillans Ice Stream. The outermost part of each margin consists of a band of large, widely spaced $(50-100 \mathrm{~m})$ arcuate crevasses. Bordering this band on the ice-stream side is the chaotic zone, with intersecting crevasses dissecting the surface. Vornberger and Whillans (1986) presume that major shearing between the ice stream and adjacent ridge occurs within this chaotic zone. The measurements of Echelmeyer and others (1994, fig. 2), confirmed this inference. Overlaying the survey stations on the RADARSAT map (Fig. 1) allows the arcuate crevasses and chaotic zone to be mapped relative to these stations. This comparison shows that maximum shearing occurs inside the chaotic zone (Fig. 5).

Vornberger and Whillans (1990) developed a simple model for the development of crevasses by calculating particle trajectories in a specified two-dimensional velocity field. The results indicate that the outermost curved crevasses are initiated by lateral shear and subsequently rotated under the combined action of flow in the down-glacier direction and transverse flow from the ridge into the ice stream. The narrow band of arcuate crevasses starts where the lateral shear stress at the surface is $\sim 130 \mathrm{kPa}$ (Fig. 6). Neglecting other components of stress acting in the horizontal plane, the corresponding principal tensile stress is $\sim 90 \mathrm{kPa}$, oriented at $45^{\circ}$. Such a stress is sufficient to initiate fracturing and crevasse formation on glacial ice (Van der Veen, 1998, 1999b).

The RADARSAT image (Fig. 1) indicates that the chaotic zone does not directly abut the band of arcuate crevasses. Instead, there appears to be a narrow zone of relatively undisturbed surface. Such a band has not been reported by previous workers, although the SPOT (Système Probatoire pour l'Observation de la Terre) image of the 'Dragon' shear margin in Whillans and Van der Veen (2001) also suggests the presence of a band with a less chaotic surface morphology separating the true chaotic zone from the outermost crevasses. A possible explanation for the crevasse-free zone is that the arcuate crevasses develop at isolated locations along the flank of the shear margin, perhaps in regions where there are transverse increases in shear stress that push the margin of the chaotic zone further towards the interstream ridge. The crevasse-free zone develops as the motion of the arcuate crevasses causes the now relict features to diverge from the edge of the chaotic zone.

\section{INTERPRETATION}

\section{Force balance on the ice stream}

The role of lateral drag in supporting the driving stress on the ice stream can be readily estimated from the following expression, derived by integrating the depth-averaged forcebalance equation over the half-width of the ice stream (Van der Veen, 1999a, section 5.6):

$$
F_{\text {lat }}=\frac{H \tau_{\mathrm{S}}}{W},
$$

where $H$ represents the ice thickness at the margin, $\tau_{\mathrm{s}}$ the maximum value of $R_{x y}$ averaged over the ice column and $W$ the half-width of the ice stream. For Whillans Ice Stream, $H=1000 \mathrm{~m}, \tau_{\mathrm{s}}=200 \mathrm{kPa}$ and $W=17 \mathrm{~km}$, giving $F_{\text {lat }}=$ $12 \mathrm{kPa}$, compared to a width-averaged driving stress of 
$13 \mathrm{kPa}$ (Stearns and others, 2005). Thus, basal drag under the ice stream accounts for only $\sim 1 \mathrm{kPa}$ of resistance to flow, confirming earlier estimates of the relative roles of basal and lateral drags. There is some uncertainty due to possible weakening of ice in the shear margin (Jackson and Kamb, 1997), but this does not affect the general conclusion that lateral drag provides most of the resistance to flow of the ice stream. It should be noted that the value for $\tau_{\mathrm{s}}$ is estimated from the lateral shear stress at the surface, using a depthaveraged value for the rate factor. While this is a sufficiently good first approximation for estimating the role of lateral drag on the motion of the ice stream, this procedure is not fully correct, as suggested by the results discussed below.

Lateral shear concentrated at the ice-stream margins must be transferred to basal drag under the shear margin or interstream ridge. The unsupported driving stress $(12 \mathrm{kPa})$ acts over a half-width of $17 \mathrm{~km}$ of the ice stream; thus, outboard of the ice stream must be a region of increased basal drag that supports a total of $2 \times 10^{8} \mathrm{~Pa}$ m. To investigate this zone of high basal drag and the nature of transfer of stress from shear in horizontal planes to vertical shear, the model developed by Whillans and Van der Veen (2001) is applied to strain measurements along the central line of survey poles.

\section{Basal drag across the margin}

The vertical shearing rate is linked to the vertical shear stress, $R_{x z}$ by invoking Glen's flow law (Van der Veen, 1999a, p. 38):

$$
\frac{\partial u}{\partial z}=2 \frac{R_{\mathrm{e}}^{n-1}}{B^{n}} R_{x z}
$$

where

$$
R_{\mathrm{e}}=\left(R_{x z}^{2}+R_{x y}^{2}\right)^{1 / 2}
$$

represents the effective shear stress. The assumption is made here that other components of stress do not contribute significantly to the effective stress. Note that all parameters in these expressions represent quantities that vary over the ice thickness and are thus functions of the vertical coordinate $z$.

Integrating Equation (4) over the full ice thickness gives

$$
u(h)-u(b)=\int_{b}^{h} 2 \frac{R_{\mathrm{e}}^{n-1}}{B^{n}} R_{x z} \mathrm{~d} z,
$$

where $z=h$ represents the upper ice surface and $z=b$ the ice/substrate interface. To evaluate the integral, the depth variation of the integrand needs to be known. Following Whillans and Van der Veen (2001), the expression

$$
\left[\frac{R_{\mathrm{e}}^{n-1}}{B^{n}} R_{X z}\right]^{1 / n}=\left(\frac{h-z}{H}\right)^{m} \frac{\tau_{\mathrm{b}}}{B_{\mathrm{b}}}
$$

is adopted, in which $\tau_{\mathrm{b}}=R_{x z}(b)$ represents basal drag in the direction of ice-stream flow and $B_{\mathrm{b}}$ represents the rate factor corresponding to the warmer, basal ice layers, where most of the vertical shearing is concentrated. Equation (7) effectively prescribes how the vertical shear strain rate, and hence the deformational component of ice velocity, varies with depth. For isothermal laminar flow, $m=1$ and the vertical shear stress increases linearly with depth from zero at the surface to the maximum value (equal to basal drag) at the bed (Van der Veen, 1999a, section 5.1). In the following analysis, the value $m=2$ is used to account for the depth variation in the rate factor. As discussed below in the sensitivity analysis, this parameter choice has little effect on the results. For the
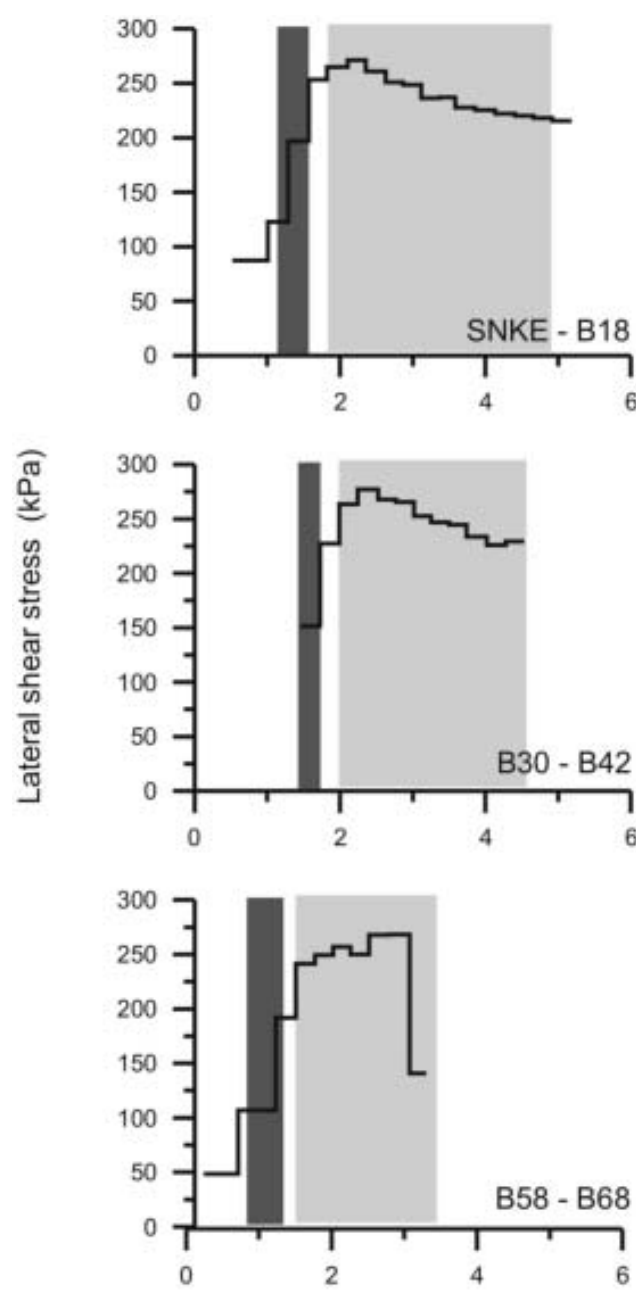

Distance along transect $(\mathrm{km})$

Fig. 6. Shear stress along the three transects, calculated from the strain rates shown in Figure 5 using Glen's flow law with a rate factor $B=700 \mathrm{kPa}^{1 / 3}$. The dark gray band corresponds to the zone of arcuate crevasses, while the light gray band represents the chaotic zone.

deep-ice rate factor, the value $B_{\mathrm{b}}=120 \mathrm{kPa}^{1 / 3}$ is adopted, following Whillans and Van der Veen (2001).

Evaluating the integral in Equation (6) yields an expression from which basal drag can be estimated:

$$
\tau_{\mathrm{b}}=B_{\mathrm{b}}\left[\frac{m n+1}{2 H} u(h)(1-S)\right]^{1 / n}
$$

(Whillans and Van der Veen, 2001). In this expression, $S=u(b) / u(h)$ represents the ratio of sliding speed and surface velocity.

To estimate basal drag from Equation (8), the sliding ratio, $S$, must be known. Because it is not a priori obvious where the transition from no-sliding to sliding is located, we start with the assumption that $S=0$ (no basal motion) along the gridline to arrive at a first guess for basal drag and integrated basal resistance under the ridge. Based on that result, the sliding parameter is estimated via forward modeling to vary in such a way that integrated basal resistance under the ridge equals the width-integrated driving stress on the ice stream.

Figure 7 shows calculated basal drag for the case of no basal slip $(S=0)$. For ease of discussion, measured surface 

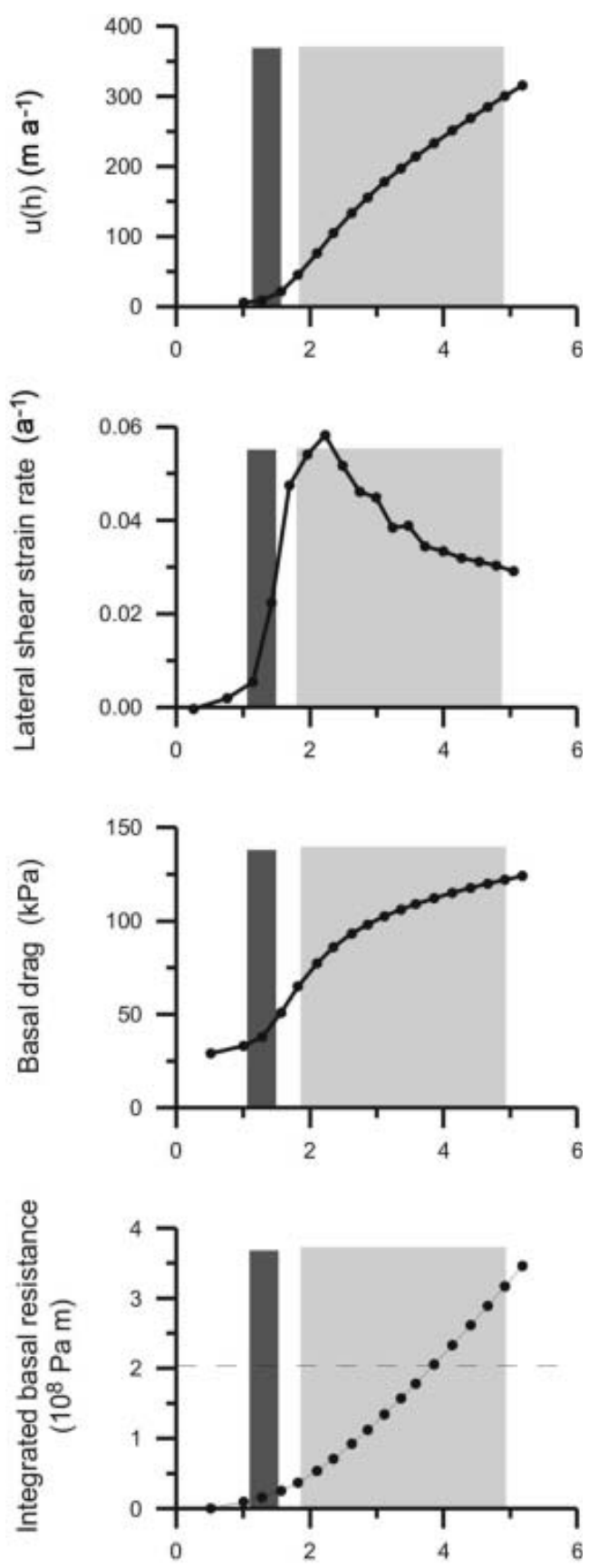

Distance along transect $(\mathrm{km})$

Fig. 7. Results of the force-balance calculation for the central line of survey poles for the case of no basal sliding. The upper panels show measured surface speed and shear strain rate. The third panel shows basal drag calculated from Equation (8). The bottom panel shows integrated basal resistance as defined in Equation (9); the horizontal dashed line corresponds to net basal resistance required to balance the driving stress on the ice stream.

speeds and derived strain rates are shown in the upper two panels. Along the survey line, basal drag increases towards the ice stream, as was to be expected because basal sliding is not included in this calculation. The bottom panel in Figure 7 shows the integrated excess basal resistance defined as

$$
F_{\text {bed }}(y)=\int_{0}^{y}\left[\tau_{b}(\bar{y})-\tau_{d}(\bar{y})\right] \mathrm{d} \bar{y},
$$

where $\tau_{\mathrm{d}}(y)$ represents the local driving stress (taken to be $12 \mathrm{kPa}$ ). The small contribution to the integral from the
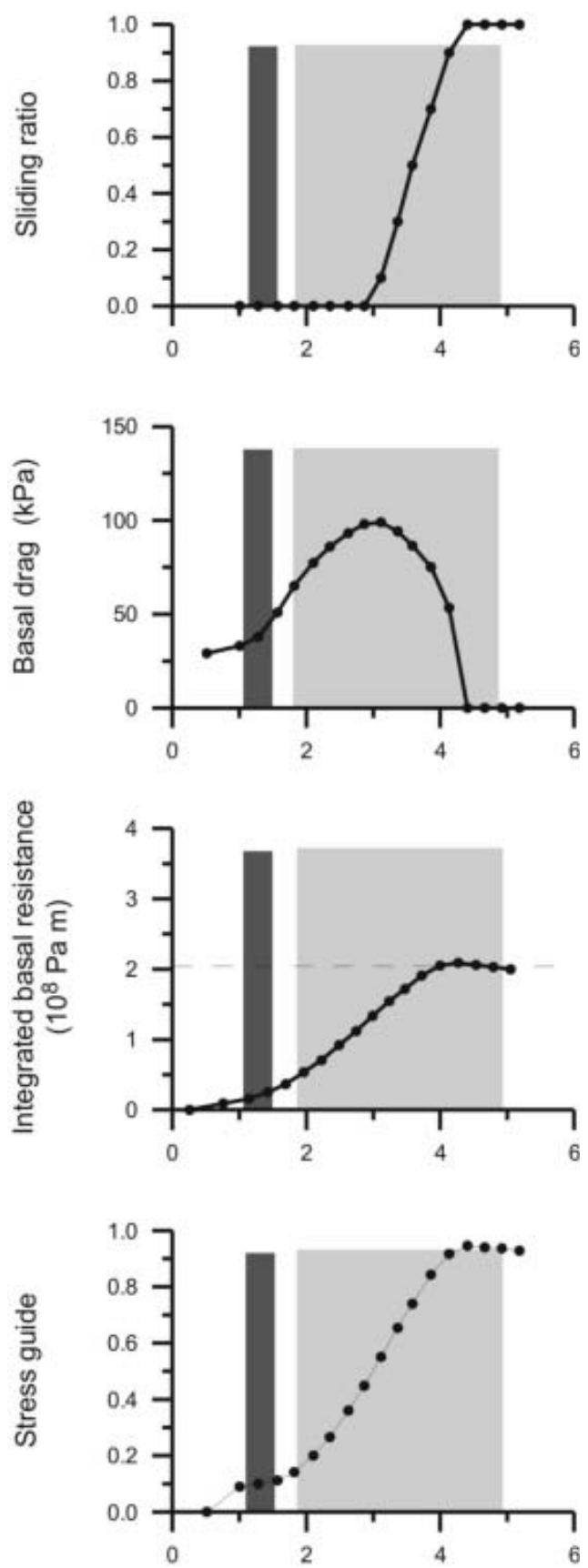

Distance along transect $(\mathrm{km})$

Fig. 8. Results of the force-balance calculation for the central line of poles with inclusion of basal sliding. The top panel shows the prescribed sliding ratio with the transition from no sliding $(S=0)$ to all sliding $(S=1)$ occurring over a zone of $\sim 2 \mathrm{~km}$ wide. The second panel shows calculated basal drag and the third panel the integrated basal resistance. The bottom panel shows the stress guide calculated from Equation (13).

region not covered by the poles is neglected. $F_{\text {bed }}$ represents resistance available to support the nearly frictionless ice stream. The total resistance actually required to support the adjacent ice stream $\left(2 \times 10^{8} \mathrm{~Pa} \mathrm{~m}\right)$ is indicated by the dashed line in the bottom panel. Thus, outboard of station B14 at $y=4.1 \mathrm{~km}$, excess basal resistance is sufficient to oppose the driving stress on the ice stream. Consequently, inboard of this station, basal drag must be significantly smaller: equal to the local driving stress or less. To achieve this, sliding must be included. One possibility is to set the sliding ratio, $S$, 
equal to unity inboard of B14. More realistic, perhaps, is to assume this ratio increases more gradually over a distance of one or two ice thicknesses. It may be noted that if the width of this transition region is too great, basal drag remains too small for $F_{\text {bed }}$ to reach the value required for balancing the driving stress on the ice stream. In other words, the transition from all sliding on the ice-stream side to no basal slip on the interstream ridge must occur over a narrow zone. Furthermore, the general shape of the functional change of the sliding ratio across the shear margin must be similar to that adopted here. For example, allowing a small component of deformational velocity on the ice stream (that is, $S<1$ ) results in too much integrated basal resistance, while shifting the transition from no-sliding to sliding more towards the interstream ridge leads to insufficient basal resistance to support the main body of the ice stream. The prescribed sliding ratio is shown in the top panel of Figure 8; corresponding basal drag and integrated basal resistance are shown in the second and third panels. After reaching a maximum slightly less than $100 \mathrm{kPa}$, basal drag decreases rapidly towards the ice stream, due to the transition from nosliding to sliding. On the ice-stream side of the survey line, basal drag is negligible. With this result, the transfer of stress can be investigated further.

\section{Transmission of stress}

The balance of forces integrated over the ice thickness reduces to (Whillans and Van der Veen, 2001)

$$
\frac{\partial}{\partial y} \int_{b}^{h} R_{x y}(z) \mathrm{d} z=\tau_{\mathrm{b}}-\tau_{\mathrm{d}}
$$

in which the $y$ axis is perpendicular to the shear margin. Following Whillans and Van der Veen (2001), a stress guide, $\phi(y)$, is introduced:

$$
\int_{b}^{h} R_{x y}(z) \mathrm{d} z=\phi(y) H R_{x y}(h) .
$$

This stress guide accounts for the depth variation in lateral shear stress and represents the fractional depth over which the surface stress acts. For the case that this stress is constant over the full ice thickness, $\phi(y)=1$. With this parameterization, the balance equation becomes

$$
\frac{\partial}{\partial y}\left[\phi(y) H R_{x y}(h)\right]=\tau_{\mathrm{b}}-\tau_{\mathrm{d}}
$$

which can be integrated to find an expression for the stress guide:

$$
\phi(y)=\frac{1}{H R_{x y}} \int_{0}^{y}\left[\tau_{\mathrm{b}}(\bar{y})-\tau_{\mathrm{d}}(\bar{y})\right] \mathrm{d} \bar{y} .
$$

Here the assumption is made that the stress-guide factor is zero at the outboard end of the survey line $(y=0)$, thus neglecting any contribution to the integral from excess basal drag outboard of the survey line. In Equation (13), $R_{x y}$ represents the lateral shear stress at the surface shown in the middle panel in Figure 6.

The calculated stress guide is shown in the bottom panel of Figure 8. On the ridge side, the stress guide is small, as was to be expected since the integrated basal resistance is small there. Going towards the ice stream, the stress guide increases to 0.94, indicating that the surface lateral shear acts over $94 \%$ of the ice thickness. As basal drag drops to zero and the integrated basal resistance starts to decrease, the stress guide begins to decrease also. The survey line does not extend far enough into the ice stream to evaluate the
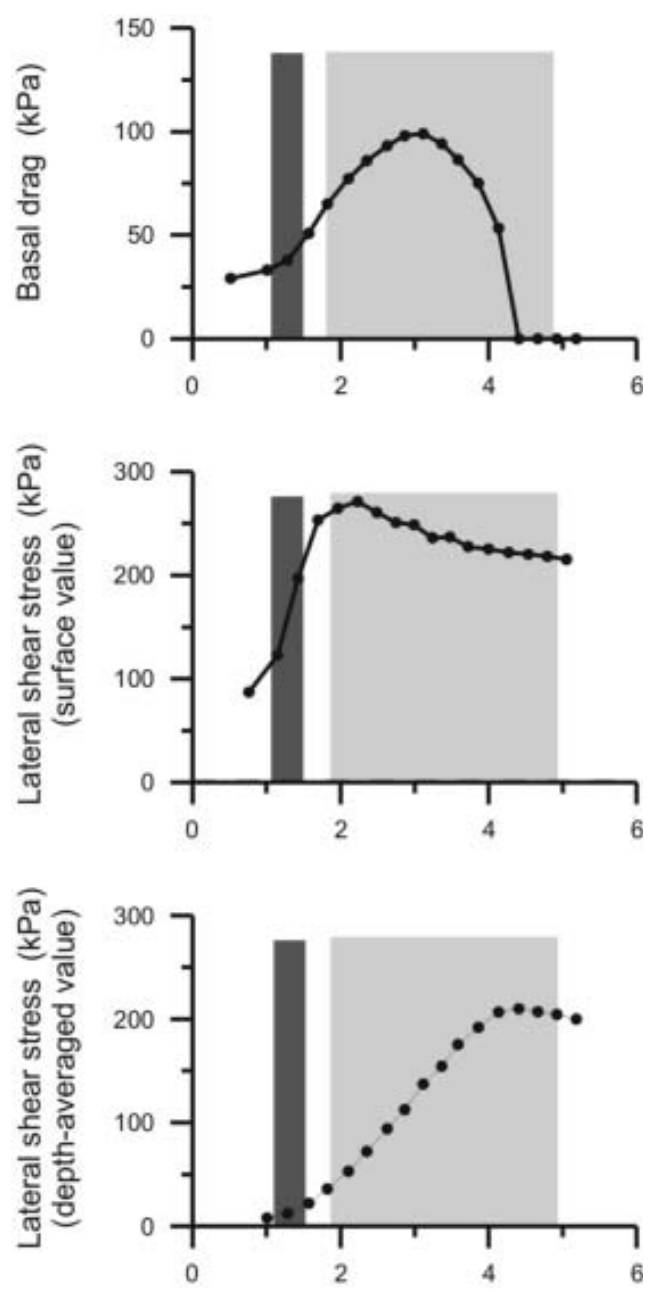

Distance along transect $(\mathrm{km})$

Fig. 9. Variation of stresses across the shear margin. The top panel shows calculated basal resistance; the middle panel shows the lateral shear stress at the surface evaluated from measured surface velocities, while the third panel shows the inferred depth-averaged lateral shear stress obtained by multiplying the surface value of the lateral shear stress and the stress guide.

stress guide on the ice stream proper, but its value there should be equal to the ratio of the depth-averaged rate factor to the surface value of the rate factor $(\sim 0.77)$.

The variation of the stress guide along the survey line is essentially different from that presented in Whillans and Van der Veen (2001, fig. 5e), which shows a decrease in stress guide from unity on the interstream ridge to about 0.4 at the ice-stream end of the Dragon grid. That result is wrong and our recalculation of the stress guide for the Dragon grid shows a pattern similar to that shown in Figure 8. A programming error caused the erroneous result presented by Whillans and Van der Veen (2001). Apart from the discussion in Whillans and Van der Veen (2001) pertaining to the stress guide and its variation across the shear margin, the conclusions reached in that paper are still supported by their analysis, and, in particular, calculated basal drag (Whillans and Van der Veen, 2001, fig. 5f) is correct inasmuch as the adopted model is correct, of course.

The maximum in basal drag is $\sim 1 \mathrm{~km}$ inboard of where lateral shearing at the surface reaches its maximum (Fig. 9). While this might appear to be violating the horizontal 

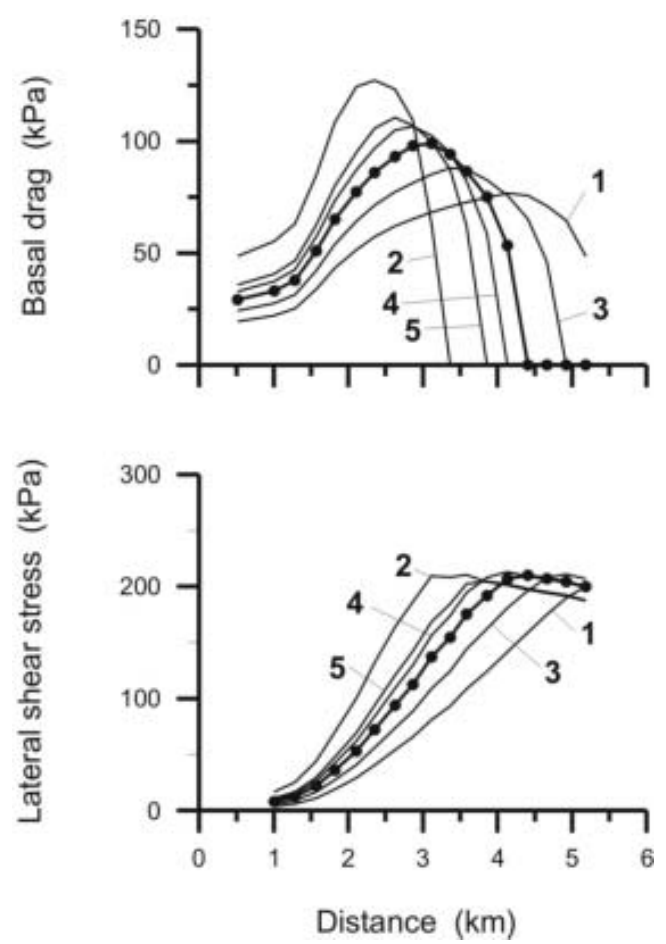

Fig. 10. Sensitivity of calculated basal drag (upper panel) and depth-averaged lateral shear stress (lower panel) to parameter values. Labeled curves correspond to: $1: B_{\mathrm{b}}=80 \mathrm{kPaa}^{1 / 3}, m=2$; 2: $B_{\mathrm{b}}=200 \mathrm{kPaa}^{1 / 3}, \quad m=2 ; 3: B_{\mathrm{b}}=120 \mathrm{kPa}^{1 / 3}, \quad m=1$; 4: $B_{\mathrm{b}}=120 \mathrm{kPaa}^{1 / 3}, m=3 ; 5: B_{\mathrm{b}}=120 \mathrm{kPaa}^{1 / 3}, m=4$.

balance equation (10), it should be kept in mind that this balance equation calls for the depth-integrated lateral shear stress. This average is obtained by multiplying the shear stress at the surface with the inferred stress guide and is shown in the third panel in Figure 9. As should be the case, the depth-averaged shear stress is maximum on the icestream side of the shear margin, where basal drag vanishes. Thus, if the margin of the ice stream is defined as the location where basal drag becomes important, that position does not coincide with where shearing at the surface is greatest. Additionally, our results indicate that the depthaveraged shear stress cannot be simply estimated from velocity gradients measured at the surface and applying an appropriate depth-averaged rate factor. This results from the contribution of both lateral and vertical shear to the effective stress in the marginal zone.

\section{Sensitivity of model results}

Two sources of uncertainty contribute to uncertainty in calculated basal drag, namely measurement errors and unknown parameter values. In Equation (8), from which basal drag is calculated, the measured quantities are the surface velocity, $u(h)$, and ice thickness, $H$, while the deep rate factor, $B_{\mathrm{b}}$, and the exponent, $m$, represent parameters whose values are uncertain.

How measurement errors affect calculated basal drag can be evaluated from the standard formula for error propagation which yields for the relative error

$$
\frac{\Delta \tau_{\mathrm{b}}}{\tau_{\mathrm{b}}}=\frac{1}{n} \frac{\Delta u(h)}{u(h)}+\frac{1}{n} \frac{\Delta H}{H} .
$$

The estimated error in GPS-determined positions is $0.01 \mathrm{~m}$ or less (Spikes and others, 2003), giving an error in velocity of about $0.015 \mathrm{~m} \mathrm{a}^{-1}$. On the ridge side of the survey line, the surface speed is $1.5 \mathrm{ma}^{-1}$ and the relative error in velocity is $10 \%$; on the ice-stream side, this relative error is significantly smaller. The corresponding relative error in calculated basal drag is thus $\sim 3 \%$ on the ridge side of the survey line and much smaller on the other end of the line (using $n=3$ ). For the ice thickness, we estimate a relative error of $10 \%$, giving a relative error in basal drag of $3 \%$. Combining the two error estimates, the relative error in calculated basal drag is $6 \%$ or less. Compared to the effects of parameter uncertainties, this error is inconsequential.

Figure 10 illustrates the sensitivity of basal drag, $\tau_{\mathrm{b}}$, and depth-averaged lateral shear stress, $\tau_{\mathrm{S}}$, to the values of the deep rate factor, $B_{\mathrm{b}}$, and exponent, $m$. Of these two parameters, uncertainty in the deep rate factor has the greatest impact on calculated basal drag and lateral shear stress. A small value (curves labeled ' 1 ') produces smaller values of basal drag and hence a wider region where drag at the glacier base exceeds the local driving stress. Increasing the rate factor has the opposite effect and leads to larger values in basal drag but over a narrower region (curves ' 2 '). As noted previously by Whillans and Van der Veen (2001), the choice for the value of the exponent $m$ in Equation (7) has only a minor effect on the model results (curves ' 3 '-'5').

\section{Meltwater production}

The narrow zone of elevated basal drag suggests that meltwater production may be important under the ridge. Assuming the basal ice is at the pressure-melting point, the rate of melting or freezing is determined by the balance between the geothermal heat flux, frictional heating associated with sliding over the bed and upward heat conduction. That is (Lingle and Brown, 1987),

$$
M=\frac{1}{L_{\mathrm{i}} \rho}\left(G-\mathrm{k} \frac{\partial T}{\partial z}(b)+\tau_{\mathrm{b}} u(b)\right),
$$

where $L_{\mathrm{i}}=333.5 \mathrm{~kJ} \mathrm{~kg}^{-1}$ represents the latent heat of fusion, $\rho=917 \mathrm{~kg} \mathrm{~m}^{-3}$ is the density of ice and $k=2.1 \mathrm{~W}(\mathrm{~m} \mathrm{~K})^{-1}$ is the thermal conductivity of ice. For the geothermal heat flux, the value $G=0.06 \mathrm{~W} \mathrm{~m}^{-2}$ (Whillans and Bindschadler, 1988) is adopted. No temperature profiles to the bed are available for the interstream ridge, and the high value measured on the adjacent ice stream, $\partial T / \partial z(b)=$ $0.04 \mathrm{~K} \mathrm{~m}^{-1}$ (Engelhardt and others, 1990) is used here. This high value may overestimate upward heat conduction and thus underestimate calculated melt rates, but the effect is minor given that frictional heating (the third term in parentheses in Equation (15)) is dominant in the region considered.

Frictional heating across the shear margin can be estimated from the results shown in Figure 8 recognizing that the basal velocity equals the surface speed multiplied by the sliding parameter. The result of this calculation is shown in Figure 11. Under the ridge where sliding is zero, the basal freeze-on rate is $\sim 2 \mathrm{~mm} \mathrm{a}^{-1}$ (this could be somewhat less if a smaller value for the basal temperature gradient is used). In the region of onset of basal sliding, the combination of sliding and high basal drag results in melting rates reaching $40 \mathrm{~mm} \mathrm{a}^{-1}$. Going further towards the ice stream, the melt rate decreases as basal drag decreases rapidly. Near the center of the ice stream, the estimated melt rate is $\sim 2 \mathrm{~mm} \mathrm{a}^{-1}$ (Stearns and others, 2005). Thus, melting under the chaotic zone is an order of magnitude greater than melt rates under 
the main body of the ice stream. We propose that this concentrated melting is the process by which shear margins migrate outward.

The estimated void ratio of till beneath Whillans Ice Stream is 0.6-0.7 (Kamb, 1991; Tulaczyk and others, 2000a). Assuming a void ratio of 0.65 , a $5 \mathrm{~m}$ thick sediment layer contains the equivalent of $2 \mathrm{~m}$ of water, corresponding to 2000 years of basal melting at a rate of $1 \mathrm{~mm} \mathrm{a}^{-1}$ (Tulaczyk and others, 2000b). Under the chaotic zone, the larger basal melt rate may allow basal sediments to become watersaturated more rapidly, resulting in a widening of the ice stream. With a melt rate of $40 \mathrm{~mm} \mathrm{a}^{-1}$, a $5 \mathrm{~m}$ thick sediment layer would be fully water-saturated after $\sim 50$ years, resulting in lowering of basal resistance and outward migration of the region of large basal drag.

\section{DISCUSSION}

While the model developed by Whillans and Van der Veen (2001) is based on a number of simplifying assumptions allowing a solution to be derived, it does incorporate the essential physical processes believed to be important in the transfer from shearing in horizontal planes to vertical shear. Perhaps the most contentious model assumption is the prescribed vertical variation in vertical shear (Equation (7)). In essence, this corresponds to prescribing the depth variation of the effective viscosity of ice. Other functional forms could be adopted, such as constant effective ice viscosity (Schoof, 2004), or exponentially increasing with height above the bed (Guomundsson and others, 1998). However, qualitatively, the results presented in Figures 7-9 are not importantly affected by the choice for the exponent, $m$, suggesting that the precise nature of the depth variation of effective viscosity is of secondary importance for calculated basal drag and lateral shear stress. The value of the deep rate factor, $B_{\mathrm{b}}$, affects the magnitude of calculated basal drag and the width of the region of large drag, but qualitatively, results are unaffected (Fig. 10). Thus, the results obtained here appear to be robust and can be used to qualitatively describe the stress transition in this shear margin. It should be pointed out that the model as formulated applied here is not a true inversion problem as implied by Schoof (2004, p. 217). Rather, measurements of surface speed are used to infer basal drag by integrating the vertical shear strain rate over the entire ice thickness, adopting Glen's flow law to link the strain rate to the vertical shear stress. By introducing the sliding ratio, the difficulty of selecting an appropriate sliding relation is circumvented here.

On the ice stream, resistance from the bed is near zero and the driving stress is balanced by gradients in lateral shearing. As the margins are approached, basal drag increases rapidly and basal conditions transition from well lubricated to no basal slip. Basal drag decreases further onto the ridge. For the northern shear margin, the zone of elevated basal drag is $\sim 4 \mathrm{~km}$ wide. This width is not significantly affected by the prescribed transition from sliding to no-sliding. Over this region, lateral drag decreases towards the ice ridge and becomes increasingly limited to acting over the upper layers only. The maximum in basal drag lies inboard of where lateral shearing at the surface is maximum.

The present model does not include enough constraints to yield a unique solution. In particular, the transition from

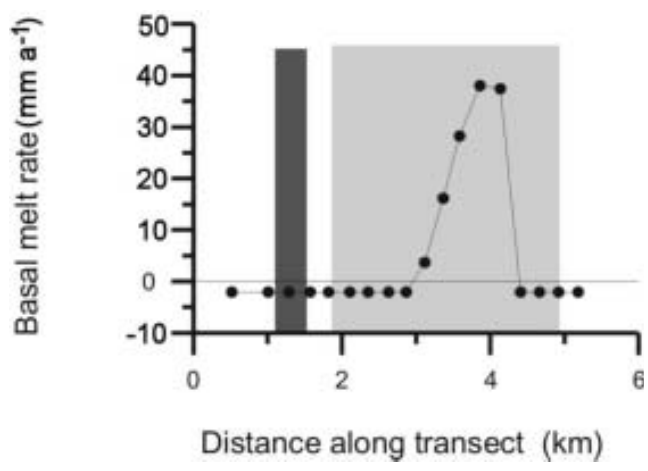

Fig. 11. Estimated basal melt rate under the middle transect. Negative melt rates correspond to basal freeze-on.

sliding to no-sliding may be different from that assumed here (Fig. 8, top panel). Nevertheless, some constraints are imposed by the requirement that basal drag across the margin must be large enough to support the adjacent ice stream. In the present model, this requires a rather narrow zone over which the sliding fraction increases from zero on the ridge side, to unity on the ice-stream side. In this narrow zone, a significant amount of meltwater is produced.

Clearly, given the inferred large value of basal resistance under the chaotic zone, this region cannot be underlain by a weak sedimentary layer as is the case under the ice stream. At the same time, some lubricating water layer must be present to allow for basal sliding. A thin water layer (several $\mathrm{mm}$ or less) separating the subglacial sediments from the ice is consistent with the low-reflectivity returns observed by Raymond and others (2006), but it appears that most of the remaining meltwater produced in the region of elevated basal drag is diverted elsewhere. Some of this meltwater may be frozen on outboard of this region, but the bulk of the water produced must either percolate downward into the sediments, or be diverted under the ice stream. Wholesale storage in subglacial sediments appears to be incompatible with the results of the radar profiling as well as the requirement of a sufficiently strong bed to support large basal drag, as this would rapidly produce a weak watersaturated sediment layer of substantial thickness. More likely is the possibility that much of the meltwater produced under the shear margin is rerouted towards the center of the ice stream, providing additional lubrication and aiding in maintaining water-saturated conditions under the ice stream required for fast flow with near-zero basal resistance.

The observation that only a fraction of the locally produced meltwater is used to mobilize subglacial sediments indicates that the available void space in these subglacial deposits must be small. As noted above, the void ratio of till under Whillans Ice Stream ranges from 0.6 to 0.7 (Kamb, 1991; Tulaczyk and others, 2000a), which would accommodate a substantial influx of meltwater. Since this does not happen, much of the void space must be filled with frozen water, and mobilizing this sediment is achieved primarily by melting of the ice occupying these voids. Given that this requires transferal of heat generated at the base of the ice to within the sediments, mobilization may be expected to be less rapid than for the case of saturating basal sediments with a significant void ratio. A further inference is that the shear margins may contribute significantly to the water balance under the ice stream. If all 
meltwater produced under the chaotic zone is distributed evenly under the ice stream, this input would correspond to $\sim 2 \mathrm{~mm} \mathrm{a}^{-1}$ of additional water (per unit area), or about twice the estimated melt rate under the ice stream.

\section{CONCLUDING REMARKS}

The present study extends the previous work of Whillans and Van der Veen (2001) in evaluating the transmission of stress from a fast-moving ice stream to the adjacent near-stagnant interstream ridge. The survey line considered in this study covers the region from vanishing basal drag under the ice stream to small basal drag on the interstream ridge. Under the chaotic zone is a narrow region ( $\sim 4 \mathrm{~km}$ wide) where drag at the glacier base is large; this excess basal drag essentially supports the driving stress on the ice stream. Further, the transition from ice motion dominated by basal sliding to internal deformation only is restricted to a narrow band, 1-2 km wide.

As concluded by Raymond and others (2006), lubrication under the shear margin must have different characteristics from that under the main body of the ice stream. Some thin layer of dilated till may be present under the margin, but most of the locally produced meltwater must be diverted under the ice stream. Our results suggest that the amount of meltwater produced under the chaotic zone is about twice the amount produced under the ice stream. This suggests that the shear margins may be controlling the motion of the ice stream not only by providing support for the gravitational driving stress, but also by facilitating weakening of sediment under the ice stream. If this view is correct, the implication is that studies of ice-stream stability that consider only the coupling between glacier speed, local basal drag and meltwater production under the ice stream may not fully incorporate all of the controlling processes.

\section{ACKNOWLEDGEMENTS}

This study would not have been initiated without the enthusiastic efforts of the late I. Whillans. We are indebted to G. Hamilton, B. Spikes, P. Braddock and S. Norman for conducting the surveys, and to C. Raymond for encouraging completion of the manuscript. Deployment of strain grids and initial data processing was supported by the US National Science Foundation (NSF) through grant OPP9615127. Subsequent data analysis and interpretation was made possible by support from NASA through NAG5-11383 and by NSF through the Center for Remote Sensing of Ice Sheets. This is Byrd Polar Research Center contribution No. C-1346.

\section{REFERENCES}

Alley, R.B. and R.A. Bindschadler, eds. 2001. The West Antarctic ice sheet: behavior and environment. Washington, DC, American Geophysical Union. (Antarctic Research Series 77.)

Alley, R.B., D.D. Blankenship, C.R. Bentley and S.T. Rooney. 1986. Deformation of till beneath Ice Stream B, West Antarctica. Nature, 322(6074), 57-59.

Bindschadler, R.A., S.N. Stephenson, D.R. MacAyeal and S. Shabtaie. 1987. Ice dynamics at the mouth of Ice Stream B, Antarctica. J. Geophys. Res., 92(B9), 8885-8894.

Catania, G.A., H.B. Conway, A.M. Gades, C.F. Raymond and H. Engelhardt. 2003. Bed reflectivity beneath inactive ice streams in West Antarctica. Ann. Glaciol., 36, 287-291.
Church, J.A. and 7 others. 2001. Changes in sea level. In Houghton, J.T. and 7 others, eds. Climate change 2001: the scientific basis. Contribution of Working Group I to the Third Assessment Report of the Intergovernmental Panel on Climate Change. Cambridge, etc., Cambridge University Press, 639-693.

Echelmeyer, K.A., W.D. Harrison, C. Larsen and J.E. Mitchell. 1994. The role of the margins in the dynamics of an active ice stream. J. Glaciol., 40(136), 527-538.

Engelhardt, H., N. Humphrey, B. Kamb and M. Fahnestock. 1990. Physical conditions at the base of a fast moving Antarctic ice stream. Science, 248(4951), 57-59.

Fahnestock, M. and J. Bamber. 2001. Morphology and surface characteristics of the West Antarctic ice sheet. In Alley, R.B. and R.A. Bindschadler, eds. The West Antarctic ice sheet: behavior and environment. Washington, DC, American Geophysical Union, 13-27. (Antarctic Research Series 77.)

Guðmundsson, G.H., C.F. Raymond and R. Bindschadler. 1998. The origin and longevity of flow stripes on Antarctic ice streams. Ann. Glaciol., 27, 145-152.

Hemming, S.R. 2004. Heinrich events: massive late Pleistocene detritus layers of the North Atlantic and their global climate imprint. Rev. Geophys., 42, RG1005. (10.1029/ 2003RG000128.)

Hodge, S.M. and S.K. Doppelhammer. 1996. Satellite imagery of the onset of streaming flow of Ice Streams C and D, West Antarctica. J. Geophys. Res., 101(C3), 6669-6677.

Hulbe, C.L. and I.M. Whillans. 1993. Stop-and-go GPS in Antarctica. Surv. Land Inf. Sys., 53(3), 150-158.

Hulbe, C.L. and I.M. Whillans. 1994. Evaluation of strain rates on Ice Stream B, Antarctica, obtained using GPS phase measurements. Ann. Glaciol., 20, 254-262.

Hulbe, C.L. and I.M. Whillans. 1997. Weak bands within Ice Stream B, West Antarctica. J. Glaciol., 43(145), 377-386.

Huybrechts, P., J. Gregory, I. Janssens and M. Wild. 2004. Modelling Antarctic and Greenland volume changes during the 20th and $21 \mathrm{st}$ centuries forced by GCM time slice integrations. Global Planet. Change, 42(1-4), 83-105.

Jackson, M. and B. Kamb. 1997. The marginal shear stress of Ice Stream B, West Antarctica. J. Glaciol., 43(145), 415-426.

Jezek, K.C. 1999. Glaciological properties of the Antarctic ice sheet from RADARSAT-1 synthetic aperture radar imagery. Ann. Glaciol., 29, 286-290.

Jezek, K.C. 2003. Observing the Antarctic ice sheet using the RADARSAT-1 synthetic aperture radar. Polar Geogr., 27(3), 197-209.

Jezek, K.C., H. Liu, Z. Zhao and B. Li. 1999. Improving a digital elevation model of Antarctica using radar remote sensing data and GIS techniques. Polar Geogr., 23(3), 185-200.

Joughin, I. and 7 others. 1999. Tributaries of West Antarctic ice streams revealed by RADARSAT interferometry. Science, 286(5438), 283-286.

Joughin, I., S. Tulaczyk, R.A. Bindschadler and S. Price. 2002. Changes in West Antarctic ice stream velocities: observation and analysis. J. Geophys. Res., 107(B11), 2289. (10.1029/ 2001JB001029.)

Kamb, B. 1991. Rheological nonlinearity and flow instability in the deforming bed mechanism of ice stream motion. J. Geophys. Res., 96(B10), 16,585-16,595.

Lingle, C.S. and T.J. Brown. 1987. A subglacial aquifer bed model and water pressure dependent basal sliding relationship for a West Antarctic ice stream. In Van der Veen, C.J. and J. Oerlemans, eds. Dynamics of the West Antarctic ice sheet. Dordrecht, etc., D. Reidel Publishing Co., 249-285.

Liu, H., K.C. Jezek and B. Li. 1999. Development of an Antarctic digital elevation model by integrating cartographic and remotely sensed data: a geographic information system based approach. J. Geophys. Res., 104(B10), 23,199-23,213.

MacAyeal, D.R., R.A. Bindschadler and T.A. Scambos. 1995. Basal friction of Ice Stream E, West Antarctica. J. Glaciol., 41(138), 247-262. 
Price, S.F., R.A. Bindschadler, C.L. Hulbe and D.D. Blankenship. 2002. Force balance along an inland tributary and onset to Ice Stream D, West Antarctica. J. Glaciol., 48(160), 20-30.

Raymond, C.F., G.A. Catania, N. Nereson and C.J. van der Veen. 2006. Bed radar reflectivity across the north margin of Whillans Ice Stream, West Antarctica, and implications for margin processes. J. Glaciol., 52(176), 3-10.

Schoof, C. 2004. On the mechanics of ice-stream shear margins. J. Glaciol., 50(169), 208-218.

Spikes, V.B., B.M. Csathó and I.M. Whillans. 2003. Laser profiling over Antarctic ice streams: methods and accuracy. J. Glaciol., 49(165), 315-322.

Stearns, L.A., K.C. Jezek and C.J. van der Veen. 2005. Decadalscale variations in ice flow along Whillans Ice Stream and its tributaries, West Antarctica. J. Glaciol., 51(172), 147-157.

Tulaczyk, S.M., B. Kamb and H.F. Engelhardt. 2000a. Basal mechanics of Ice Stream B, West Antarctica. I. Till mechanics. J. Geophys. Res., 105(B1), 463-481.

Tulaczyk, S.M., B. Kamb and H.F. Engelhardt. 2000b. Basal mechanics of Ice Stream B, West Antarctica. II. Undrained-plastic-bed model. J. Geophys. Res., 105(B1), 483-494.

Tulaczyk, S., B. Kamb and H.F. Engelhardt. 2001. Estimates of effective stress beneath a modern West Antarctic ice stream from till preconsolidation and void ratio. Boreas, $\mathbf{3 0}(2)$, $101-114$.

Van der Veen, C.J. 1998. Fracture mechanics approach to penetration of surface crevasses on glaciers. Cold Reg. Sci. Technol., 27(1), 31-47.
Van der Veen, C.J. 1999a. Crevasses on glaciers. Polar Geogr., 23(3), 213-245.

Van der Veen, C.J. 1999b. Fundamentals of glacier dynamics. Rotterdam, etc., A.A. Balkema Publishers.

Vornberger, P.L. and I.M. Whillans. 1986. Surface features of Ice Stream B, Marie Byrd Land, West Antarctica. Ann. Glaciol., 8, 168-170.

Vornberger, P.L. and I.M. Whillans. 1990. Crevasse deformation and examples from Ice Stream B, Antarctica. J. Glaciol., 36(122), 3-10.

Whillans, I.M. and R.A. Bindschadler. 1988. Mass balance of Ice Stream B, West Antarctica. Ann. Glaciol., 11, 187-193.

Whillans, I.M. and C.J. van der Veen. 1993. New and improved determinations of velocity of Ice Streams B and C, West Antarctica. J. Glaciol., 39(133), 483-490.

Whillans, I.M. and C.J. van der Veen. 1997. The role of lateral drag in the dynamics of Ice Stream B, Antarctica. J. Glaciol., 43(144), 231-237.

Whillans, I.M. and C.J. van der Veen. 2001. Transmission of stress between an ice stream and interstream ridge. J. Glaciol., 47(158), 433-440.

Whillans, I.M., C.R. Bentley and C.J. van der Veen. 2001. Ice Streams B and C. In Alley, R.B. and R.A. Bindschadler, eds. The West Antarctic ice sheet: behavior and environment. Washington, DC, American Geophysical Union, 257-281. (Antarctic Research Series 77.)

Zumberge, J.F., M.B. Heflin, D.C. Jefferson, M.M. Watkins and F.H. Webb. 1997. Precise point positioning for the efficient and robust analysis of GPS data from large networks. J. Geophys. Res., 102(B3), 5005-5017.

MS received 13 January 2006 and accepted in revised form 14 October 2006 